\title{
PENSAR EL CINE. LA NARRATIVA DE PELÍCULAS Y SERIES COMO MATRIZ METODOLÓGICA PARA EL TRATAMIENTO DE PROBLEMAS COMPLEJOS
}

\author{
THINKING CINEMA. THE NARRATIVE OF FILMS AND TV SERIES AS A \\ METHODOLOGICAL MATRIX FOR THE TREATMENT OF COMPLEX PROBLEMS
}

\author{
Irene Cambra Badii \\ (CONICET - Universidad de Buenos Aires) \\ cambrabadii@psi.uba.ar
}

Recibido: 06/06/2018

Aprobado: 11/07/2018

\begin{abstract}
RESUMEN
En este artículo presentamos los avances del proyecto de investigación de la Universidad de Buenos Aires que busca puntualizar la indagación sobre la articulación entre Cine y Psicología, proponiendo la formalización de un método de investigación en psicología a partir del formato audiovisual. Nuestro punto de partida coincide con la consigna del filósofo francés Alain Badiou, quien propone "pensar el cine”, es decir, no sólo analizar los conceptos asociados con el dispositivo cinematográfico, sino más bien pensar los conceptos a través del cine. En primer lugar presentamos una indagación conceptual del Estado del arte sobre los tres grandes campos de estudios sobre el cine que resultan antecedentes ineludibles para poder adentrarnos en la temática: los estudios tradicionales sobre cine en relación con la historización de sus posibilidades técnicas y sus manifestaciones artísticas, los diferentes géneros cinematográficos, y los recursos técnico-estilísticos utilizados; el estudio de la narratividad, es decir, en los aspectos ligados al relato y a la argumentación que se esgrime en la estructura narrativa del film o de la serie; y la utilización del cine como herramienta didáctica, considerando distintos filmes como “ejemplos” y como aplicaciones conceptuales de la discursividad social en el campo fílmico. En segundo lugar, proponemos dar un paso más, integrando las tres corrientes antes mencionadas e incluyendo un movimiento suplementario a partir de la lectura de Deleuze y Badiou: considerar al cine como una vía de acceso conceptual a problemáticas complejas del campo de la subjetividad. Esto implica que el cine permite estructurar nuevos modelos metodológicos de comprensión o incluso de creación de problemas complejos en el marco de la psicología, en un equilibrio que incluye tanto a la deliberación sobre los conceptos como la experiencia estética y artística de la narrativa audiovisual.
\end{abstract}

Palabras clave: cine, psicología, metodología de la investigación.

\section{ABSTRACT}

In this article, we present the advances of the University of Buenos Aires research project that seeks to clarify the inquiry about the articulation between Cinema and Psychology, putting forward the formalization of a research methodology in psychology based on 
audiovisual format. Our starting point coincides with French philosopher Alain Badiou's key principle, as he proposes "thinking cinema", that is, not only analyzing the concepts associated with the cinematographic device, but rather thinking about the concepts through cinema. First, we present a conceptual inquiry into the state of art on the three major fields of studies on cinema that are unavoidable antecedents to be able to study the subject thoroughly: traditional studies on cinema in relation to the historization of its technical possibilities and its artistic manifestations, the different film genres, and the technicalstylistic resources used; the study of narrativity, that is, the aspects linked to the story and the argumentation that is developed in the narrative structure of the film or the series; and the use of cinema as a didactic tool, considering different films as "examples" and as conceptual applications of social discourse in the film field. Secondly, we propose to go a step further, integrating the three currents mentioned above and including a supplementary movement based on the reading of Deleuze and Badiou: considering cinema as a conceptual access to complex problems in the field of subjectivity. This implies that cinema allows the structuring of new methodological models of understanding or even the creation of complex problems within the framework of psychology, keeping both the deliberation about concepts and the aesthetic and artistic experience of audiovisual narrative in balance.

Keywords: cinema, psychology, methodology

\section{Introducción: cine y subjetividad}

Nuestro punto de partida coincide con la consigna del filósofo francés Alain Badiou (2004), quien propone la acción de "pensar el cine", ya que lo entiende no sólo como arte sino también como experimentación de pensamiento. ¿Qué significa esto? Que el cine no es sólo un fenómeno artístico, cuyo fin puede ser el entretenimiento o la transformación subjetiva del espectador, sino que también se convierte en una usina de pensamiento, en una posibilidad de pensar conceptos nuevos a través del cine mismo.

Desde la Psicología y las demás ciencias sociales, frecuentemente nos planteamos diversos problemas y tensiones conceptuales. Estos puntos de interrogación no sólo tienen que ver con el campo profesional (por ejemplo, respecto del rol del psicólogo, sus responsabilidades y competencias; lo cual también puede pensarse para la sociología, el trabajo social, la historia, entre otras disciplinas...) sino también con el campo conceptual, con el despliegue del marco teórico a partir del cual se desenvuelve el trabajo cotidiano.

El foco central de este trabajo radica en la propuesta de entender al cine como una posibilidad de acceso privilegiada a estas tensiones conceptuales, mediante un análisis que incluya tanto las cuestiones técnicoestilísticas del film como la historia narrada.

\section{Antecedentes: el cine como técnica, como discurso, como herramienta}

Los estudios sobre cine son tan amplios como las disciplinas con las cuales dialoga: la comunicación, la sociología, la psicología, la educación, entre otras.

Consideramos que existen tres grandes campos de estudios sobre el cine que resultan antecedentes ineludibles para poder adentrarnos en la temática.

Podemos ubicar, en primer lugar, los estudios tradicionales sobre cine en relación con la historización de sus posibilidades técnicas y sus manifestaciones artísticas, los diferentes géneros cinematográficos, y los recursos técnico-estilísticos utilizados (Aumont y Marie, 2006; Casetti y Di Chio, 1994; Casetti y Gromegna, 1989; Chion, 1993; Metz, 1972). Los análisis toman en cuenta la 
representabilidad fílmica, sus reglas, los dispositivos utilizados y los condicionamientos técnicos, otorgándoles un sentido.

La historización del cine y sus posibilidades técnicas (con las transformaciones que conlleva el paso del cine mudo al cine sonoro, por ejemplo) resulta interesante en función de comprender cómo la imagen proyectada se sirve de determinados recursos técnico-estilísticos para el desarrollo de una historia, o para producir distintas reacciones en el espectador.

Las técnicas del cine han sido estudiadas por infinidad de teóricos. Morin (2001) incluye la movilidad de la cámara, la sucesión de los planos, la persecución del elemento emocionante, la aceleración, la música, la asimilación de un medio y de una situación por aprehensión, las envolturas (movimientos y posiciones de la cámara), ralentissement y condensación del tiempo, fascinación macroscópica (primer plano), iluminación (sombras, luces), ángulos de encuadre (picado, contrapicado, etc.).

Dentro de los recursos técnico-estilísticos, el montaje se ubica en un lugar privilegiado. Ya desde los estudios clásicos sobre la imagen cinematográfica se considera al montaje como una técnica suprema, porque el tiempo del cine "pone de acuerdo los fragmentos temporales según un ritmo en particular que no es el de la acción, sino el de las imágenes de la acción” (Morin, 2001, p. 57).

Sel y Gagioli (2002) señalan que la técnica del montaje puede ser analizada desde dos grandes tendencias, que resuenan en distintos efectos: una que sigue a Serguei Eisenstein y considera que cada toma existe como una representación particular de un film organizado como un "todo" a la vista del espectador, a quien se dirige hacia determinado objeto o movimiento; y otra, representada por André Bazin, que desvaloriza el montaje como tal y considera que no es más que la representación realista del film, transparente frente al espectador, y que por lo tanto se debe dejar que éste elija qué mirar. Vemos entonces que no solamente se enfocan en en la técnica cinematográfica en sí, sino más bien en los efectos que suscitan en el espectador.

Esta temporalidad nueva del cine a través del montaje configura una experiencia acelerada o ralentizada, donde es posible incluso la reversibilidad (a través del flash back y del cut back) enfatizando una vez más el efecto que produce la técnica: se trata de un tiempo psicológico, es decir, subjetivo, afectivo, en palabras de Bergson (2016): en un vivido indefinible de pasado, presente y futuro. Lo mismo opera con la espacialidad: el film permite transportar al espectador a cualquier punto del tiempo y del espacio (Morin, 2001).

Morin (2001) da un paso más y señala que, en la historización del cine, a la metamorfosis espaciotemporal se suma el universo de la ficción en el cine como un aspecto de radical importancia para su análisis. Esto implica, esencialmente, el contar una historia.

Ubicamos entonces una segunda tradición investigativa, que se centra en el estudio de la narratividad del cine (Barthes, 1970; Bajtin, 1982; Betettini, 1984; Gaudreault, Jost y Pujol, 1995), es decir, en los aspectos ligados a la narración, a la descripción de la historia y a la argumentación que se esgrime en la estructura narrativa del film.

Las narrativas han sido, desde tiempos inmemoriales, una vía directa de transmisión e interrogación de experiencias, emociones y saberes. Su fecundidad radica, justamente, en que la vida misma tiene una estructura que podríamos llamar narrativa (Ricoeur, 2006) y también podemos acercarnos a distintas experiencias por la vía de relatos -literarios, musicales, cinematográficos.

Evidentemente, esta línea de estudio del cine se basa en los aportes teóricos de la crítica literaria. Por ejemplo, Gerard Genette (1989) propone distinguir la historia, el relato y la narración dentro del texto narrativo (que puede ser tanto literario como fílmico). La historia está definida como el contenido narrativo, es decir, la sucesión de acontecimientos narrados. El universo en el que transcurre la historia ficcional es llamado diégesis. El relato, por otra parte, es el enunciado narrativo, el discurso en el cual se materializa la historia -las imágenes, la música... "significantes organizados en función del estilo, 
género, orden y ritmo” (Triquell, 2012, p. 41). La narración, por último, se refiere al acto narrativo productor de relato, es decir, a la enunciación.

Estas instancias teóricas no son independientes de los recursos técnico-estilísticos. De hecho, Francois Jost (2002) considera que la posibilidad de reconocer la presencia de una instancia enunciativa (es decir, reconocer los deícticos, que en una narración escrita pueden ser a través de los adverbios, por ejemplo: aquí, ahora, yo) se produce fundamentalmente a partir de determinadas opciones de encuadre: el primer plano, el descenso del punto de vista por debajo del nivel de los ojos, la representación de una parte del cuerpo en primer plano, la sombra del personaje, entre otras cuestiones. Esta percepción de la instancia enunciativa varía según el espectador, su conocimiento del lenguaje cinematográfico, y la época.

Sin embargo, la atención de los enfoques narratológicos está puesta en EL relato y sus formas de manifestarse, en los factores estructurales de la historia, que pueden entenderse como los acontecimientos y sus transformaciones, tanto a nivel de las situaciones como de los personajes, su punto de vista y focalización, entre otras cuestiones.

Según Casetti y Di Chio (1994), la literatura relativa únicamente a la dimensión narrativa del cine parece haber sido desestimada poco a poco, básicamente por dos confusiones: por un lado, porque las formas de no-narratividad son bastante reducidas y además el cine siempre ha contado historias; y por otro lado, no resulta claro que la dimensión narrativa pertenezca a los contenidos de la imagen, o al modo en que éstas se organizan, relacionan y presentan, es decir, al relato o a su forma de presentación.

El tercer campo de estudio sobre el cine es aquel que lo define como herramienta didáctica en múltiples disciplinas.

El cine, las series televisivas y otros soportes audiovisuales han sido utilizados en distintas situaciones de enseñanza y de aprendizaje, con el fin de instalar la reflexión y el pensamiento crítico, o bien con el objetivo de ilustrar mediante ejemplos los contenidos teóricos de determinados cursos de las ciencias sociales, exactas y naturales (Perales Palacios, 2006; Hernández Figaredo y Peña García, 2015).

Frente a las iniciales resistencias, que consideraban al cine y a la televisión como meros "distractores" en la hora de clase (Calvert, Casey, Casey, French y Lewis, 2007), que incluso pueden degradar el pensamiento simbólico (Sartori, 1998), la incorporación pedagógica del cine de ficción por parte de los docentes fue in crescendo en las últimas décadas, lo cual produjo una defensa de las ficciones cinematográficas como dispositivos de aprendizaje (Mateus, 2017).

Las estrategias didácticas que utilizan el cine consideran que constituye un recurso flexible capaz de complementar los métodos docentes clásicos (Dark, 2005). Las imágenes y las historias relatadas aportan elementos que generan entusiasmo, a la vez que amplían el conocimiento conceptual y fomentan las capacidades críticas de los estudiantes ya sea en su capacidad emocional (Ferres, 2014) o cognitiva (Piscitelli, 2012).

También posibilitan el diseño de prácticas educativas que promueven la crítica, la observación, la reflexión e incluso la investigación (García Borrás, 2008). Una escena cinematográfica puede actuar como elemento motivador, para introducir de cierta discusión y al mismo tiempo, como detector de preconcepciones, además de servir para el desarrollo del espíritu crítico y la actitud científica, lo cual ha llevado al análisis de las prácticas con películas en el aula y los supuestos acerca de las posibilidades pedagógicas de las imágenes (Benasayag, 2017).

\section{El Cine en su dimensión conceptual}

En esta investigación pretendemos dar un paso más, integrando las tres corrientes antes mencionadas, y proponiendo además un movimiento suplementario: considerar al cine como una vía de acceso conceptual a problemáticas complejas del campo de la subjetividad. Esto implica que pensar el cine 
permite estructurar nuevos modelos metodológicos de comprensión o incluso de creación de problemas complejos en el marco de la psicología, en un equilibrio que incluye tanto a la deliberación sobre los conceptos como la experiencia estética y artística de la narrativa audiovisual.

Entendemos el término "subjetividad” en una acepción amplia, definiéndolo como formas sedimentadas de relacionarse con el mundo, organizadas según los modos de decirlo y al mismo tiempo de significarlo (Dalmasso, 2005). Este concepto permite contemplar la pluralidad de discursos y prácticas que regulan la producción sociocultural de sentido, entendiendo que se trata de un proceso complejo que incluye un entramado de representaciones socio-culturales, prejuicios, temores, fantasías inconscientes.

El cine, que ha sido catalogado como una síntesis de las artes precedentes (Canudo, 1914; Badiou, 2004), se presenta asimismo como una forma privilegiada para acceder a un recorte singular a través de un fragmento de pocos minutos de duración que nos permite pensar cuestiones complejas de la subjetividad. ¿A partir de qué autores podemos emplazar conceptualmente esta cuestión?

Gilles Deleuze ([1983]1984, [1985]1987) resulta sin lugar a dudas uno de los antecedentes imprescindibles a la hora de estudiar al cine como concepto. En sus obras célebres Cine 1: la imagenmovimiento y Cine 2: La imagen-tiempo, estudia y clasifica los dos tipos de imágenes que dan título a sus libros. Deleuze analiza las composiciones de imágenes y signos por parte de los grandes autores del cine, proponiendo como hipótesis central que el pensamiento opera con los signos ópticos y sonoros de la imagen-movimiento, y también de una imagen-tiempo más profunda, para producir a veces grandes obras. La pregunta “¿qué pasa en el cine?”, sobre la ontología de la imagen cinematográfica, configura así un campo de estudio original para el cual toma los aportes de Henri Bergson para introducir la cuestión de que la imagen no es una copia de la realidad ontológica exterior:

Es falso reducir la materia a la representación que tenemos de ella, falso también hacer de ella una cosa que produciría en nosotros representaciones pero que sería de otra naturaleza que estas. La materia, para nosotros, es un conjunto de "imágenes”. Y por “imagen” entendemos una cierta existencia que es más que lo que el idealismo llama representación, pero menos que lo que el realismo llama una cosa, una existencia situada a medio camino entre la “cosa” y la “representación” (Bergson, 2006, pp. 25-26)

La imagen, entonces, queda ubicada en un plano intermedio, y evoca un contenido de pensamiento bajo una forma más fluida y menos abstracta que el concepto (Vollet, 2006).

Por su parte, en la escena latinoamericana, Julio Cabrera aúna en Cine: 100 años de filosofía (1999) sus dos grandes pasiones: el cine y la filosofía. Partiendo de la base de que la filosofía no debe presuponerse como algo perfectamente definido antes del surgimiento del cine, sino como una disciplina que puede modificarse a través de ese mismo nacimiento, Cabrera analiza en este libro, su tesis doctoral, distintas películas elegidas cuidadosamente para reflexionar sobre una cuestión filosófica central. Su aporte conceptual central dialoga con la propuesta deleuziana y propone que existen conceptos-imagen, que son un tipo de "concepto visual” con una estructura radicalmente diferente a los conceptos tradicionales utilizados por la Filosofía escrita (denominados por Cabrera como conceptos-idea).

Los conceptos visuales se instauran y funcionan dentro del contexto de una experiencia, que lleva a una comprensión logopática, que combina el Logos y el Ethos, es decir, que es racional y afectiva al mismo tiempo:

La racionalidad logopática del Cine cambia la estructura habitualmente aceptada del saber, en cuanto es definido sólo lógica o intelectualmente. Saber algo, desde el punto de vista logopático, no consiste solamente en tener "informaciones", sino también en haberse abierto a cierto tipo de experiencia, y en haber aceptado dejarse afectar por alguna cosa desde dentro de ella misma, en una experiencia vivida (Cabrera, 1999, pp. 18-19).

Tanto Deleuze como Cabrera coinciden entonces en la propuesta del cine como concepto. En la misma línea, Badiou enuncia la pregunta: 
¿Es posible comprender un pensamiento acerca del cine a partir de la noción de imagen? ¿De imagen en movimiento? ¿De lo que Gilles Deleuze llama precisamente la imagen-movimiento? Me parece que el punto esencial es sostener que lo real del cine son los filmes, son las operaciones convocadas en algunos filmes. Así como hay poesía sólo en la medida en que primero hay poemas, del mismo modo solo hay cine en la medida en que hay filmes. Y un filme no es la realización de las categorías, incluso materiales, que en él se suponen: categorías como imagen, movimiento, marco, fuera de campo, textura, color, texto, y así sucesivamente. Un filme es una singularidad operatoria, ella misma captada en el proceso masivo de una configuración de arte (Badiou, 2011, p. 19).

Esta singularidad operatoria será una de las categorías ineludibles para pensar el estudio de la subjetividad en una metodología que articule el Cine y la Psicología, tal como veremos más adelante.

\title{
El cine desde y para la psicología: un campo para explorar
}

Aumont y Marie (2006) señalan que la Psicología puede articularse con los estudios sobre cine en múltiples niveles:

1) El estudio de los films como producciones sintomáticas de su director.

2) El estudio de la obra en sí misma, en el nivel de sus temas manifiestos.

3) La investigación clínica del comportamiento de los personajes en el seno de la obra

4) La investigación del conjunto del material fílmico, independientemente del argumento manifiesto, como algunas figuras visuales recurrentes (por ejemplo, el fundido encadenado, la fragmentación del montaje, la elipsis).

5) El estudio de los grandes regímenes discursivos que caracterizan a la institución cinematográfica: la división entre films narrativo-representativos y films no narrativos, la división en géneros con su lógica narrativa interna, la verosimilitud.

6) El estudio del dispositivo fílmico en general, como condición particular de captar imágenes como "significante imaginario".

7) El estudio del espectador de cine y sus reacciones psíquicas frente a la realidad proyectada en el film.

Tal como vemos, se pueden ubicar aspectos ligados a la psicología y al psicoanálisis, distinción que excede los límites de este trabajo. Sin embargo, es interesante puntualizar en una cuestión: el interés que el cine tiene para el campo de la psicología y, podríamos agregar, para las demás ciencias sociales.

En este punto, un antecedente teórico e histórico ineludible, aunque poco conocido, es la pequeña carta que escribió la psicoanalista Lou Andreas-Salomé en 1913, luego de haber ido al cine:

¿Cómo es posible que el cine no suponga lo más mínimo para nosotros?; no es ésta la primera vez que me lo pregunto.

\begin{abstract}
A los muchos argumentos que podríamos esgrimir en favor de esta cenicienta de la concepción estética del arte, corresponde añadir también un par de consideraciones puramente psicológicas. Una hace referencia a que la técnica cinematográfica es la única que permite una tal rapidez en la sucesión de las imágenes que se corresponde más o menos a nuestras propias facultades de representación, imitando en parte su carácter caprichoso. Una parte del cansancio que nos invade en las representaciones teatrales no proviene del noble afán que exige la contemplación artística, sino del esfuerzo de adaptación impuesto por la pesadez del movimiento aparente de la vida en la escena; en el cine, sin un esfuerzo semejante, se libera gran parte de nuestra atención permitiéndonos que nos rindamos más espontáneamente a la ilusión.
\end{abstract}

La segunda consideración concierne al hecho de que, aunque se puede hablar de una simple satisfacción superficial, ésta obsequia a nuestros sentidos con una profusión de formas, imágenes e impresiones de modo totalmente particular y, tanto para el trabajador enmudecido por la estrechez de su vida cotidiana, como para el intelectual aferrado al trajín de su profesión o de su pensamiento, significa ya de por sí un rastro de vivencia artística de las cosas. Ambos argumentos obligan, por lo tanto, a una reflexión sobre lo que el futuro del cine puede llegar a significar para nuestra constitución psíquica, la pequeña zapatilla dorada de la cenicienta de las artes (Andreas-Salomé, [1913] 1977, pp. 101-102). 
Este hermoso pasaje, que no tiene aún demasiada difusión como antecedente en los estudios sobre cine y psicología (salvo en los escritos de Zimmerman, 2000; y Michel Fariña y Gutiérrez, 1999), es sin dudas nodal para esta articulación, y puede encontrarse en relación tanto con los estudios de Deleuze y Cabrera, como los de Badiou.

En efecto, las imágenes proyectadas en la pantalla tienen un carácter movilizador, y esta modificación del carácter a partir de la experiencia cinematográfica sin dudas tiene correlato con la vivencia de la batalla, del cuerpo a cuerpo, que señala Badiou (2004) respecto de la implicación del espectador en aquello que ve en la pantalla, pero vive como experiencia propia, sumergiéndose en la escena.

Mediante mecanismos psíquicos tales como la identificación, la proyección, etc., el espectador se vincula con los personajes y las situaciones planteados, y en algunos casos, se produce la interpelación: ¿Qué haría yo en su lugar? ¿Qué me pasa a mí con lo que está siendo relatado en el film? ¿Qué pasaría si...? Sin lugar a dudas, este proceso vivencial es subjetivo.

La pregunta por lo subjetivo en la experiencia cinematográfica durante mucho tiempo ha versado sobre la identificación, si bien se trataba de un uso vulgar, bastante amplio e impreciso del término. Según Aumont, Bergala, Marie y Vernet (2011) se utilizaba para designar la relación subjetiva que el espectador puede mantener con este o aquel personaje del film, es decir, esa experiencia del espectador que consiste en colocarse en su lugar o "tomarse momentáneamente por él”. Si bien el fenómeno identificatorio efectivamente ocurre, es importante notar que también "el espectador se identifica con su propia mirada y se experimenta como foco de la representación, como sujeto privilegiado, central y trascendental de la visión” (Aumont, Bergala, Marie y Vernet, 2011, p. 264), lo cual se conoce como identificación primaria en el cine -concepto que difiere de lo que se entiende por identificación primaria en el psicoanálisis-. Esta noción explica que no es indispensable que en un film aparezca la imagen de los demás, del semejante, para que se produzca este tipo de experiencia en el espectador. Entonces, podría pensarse que se trata de algo estructural, que no depende del guion o los personajes, sino que, en palabras de Georges Bataille, "poco más o menos, todo hombre se implica en los relatos, en las novelas, que le revelan la verdad múltiple de la vida” (citado en Aumont et al, 2011, p. 266-267).

En efecto, el proceso de identificación del espectador con los personajes y el contenido del film favorece su involucración afectiva e intelectual, y permite elaborar cuestiones mediante el mecanismo de proyección: identificando en el personaje reacciones, sentimientos, emociones, puede ir desplegando ese camino en el propio proceso, implicando una proyección del mundo y no sólo de la experiencia vivida como espectador.

Si nuestra participación como espectadores de un film o de una serie es de implicación e incluso de identificación, pudiendo aunar en un mismo acto la empatía con una situación o con los personajes que la representan, y la aprehensión de una cierta lógica que articula la contingencia, las cuestiones azarosas, con la coherencia del sentido y la causalidad, entonces debemos tomar esta cuestión como central en nuestros estudios. Esto implica, desde ya, superar la vieja dicotomía de la objetividad versus subjetividad, dado que no existe un visionado imparcial de un film, pero a su vez es esa implicación la que permite una mirada singular del film.

\section{El cine como herramienta metodológica para el estudio de la subjetividad}

Todos los puntos detallados anteriormente respecto de la articulación entre cine y psicología (Aumont y Marie, 2006) forman parte de corrientes interpretativas que redundan en aportes para ambas disciplinas, aunque pueden encuadrarse dentro de los juicios indistinto y diacrítico mencionados por Badiou (2011).

El filósofo francés señala tres modalidades para el visionado y la apreciación de una obra cinematográfica, estudiadas asimismo por Eduardo Laso (2018). 
En la primera de ellas, denominada juicio indistinto, se produce una evaluación del film en base a si la experiencia de su visionado fue agradable o desagradable. Las respuestas se organizan en pares de oposiciones: me gustó/no me gustó, me divirtió/me aburrió.

En la segunda, llamada juicio diacrítico, el foco está puesto en el conocimiento acerca de la película, el director y la historia del cine. La evaluación se convierte en "un juicio cinéfilo en el que se mide el valor estético en función de un saber más o menos consagrado (que, por supuesto, envejece pronto)” (Laso, 2018, p. 10). Esta adecuación -o no- a los cánones cinematográficos de una época también da como resultado una opinión que a menudo puede dividirse como bueno/malo, a favor/en contra.

La tercera, el juicio axiomático, se refiere a la posibilidad de pensar un film-idea: "hablar de un film es examinar las consecuencias del modo propio en que una idea es tratada así por ese filme” (Badiou, 2011, p. 30). Tal como señala Laso (2018, p. 10):

\begin{abstract}
El juicio axiomático se basa en el film en sí mismo en tanto objeto estético que vehiculiza una idea y abre a la pregunta por sus efectos a nivel del pensamiento. ¿Cómo llega a ser tratada la idea en función de la cual se hizo la película? ¿Qué consecuencias tiene el modo de tratamiento? Este abordaje trasciende el gusto inmediato y el juicio erudito, para centrarse en el problema de si el film es justo -en el sentido de ajustado y de verdadero- respecto de lo que intenta transmitir. Un buen film se vale de sus especiales recursos para introducirnos en problemas y llevarnos a sentirlos y también pensarlos. Hace pensar, en tanto transmite ideas encarnadas en situaciones y personajes. Y si ofrece alguna solución, dado que ésta es singular y relativa a la historia que relata, no alcanza nunca a ser una respuesta definitiva (como tampoco aspira a hacerlo).
\end{abstract}

Es a partir de esta tercera modalidad que planteamos la posibilidad de trabajar con el cine en una metodología rigurosa el estudio de la subjetividad, en una retroalimentación de conceptos con la Psicología.

Por supuesto, nuestra metodología de análisis puede entenderse desde las bases del enfoque cualitativo, que incluye en su comprensión epistemológica una perspectiva centrada en el sentido, en la comprensión y en el significado (Taylor y Bogdan, 2013); y está sostenida por métodos de análisis y explicación que abarcan la comprensión de la complejidad, el detalle, el contexto, y que incluyen lo singular (Mason, 1996).

Asimismo, para este abordaje metodológico del cine seguimos el método clínico-analítico de lectura de filmes (Michel Fariña, 2015), que se basa en el paradigma indiciario de Carlo Guinzburg y el método abductivo de Charles Peirce.

El paradigma indiciario de Carlo Guinzburg (2008) propone una tarea de pesquisa e indagación pormenorizada, detección de datos marginales y privilegio de detalles poco perceptibles a primera vista, a la manera de un cazador o detective. Por otra parte, el método abductivo de Charles Peirce trabaja generando hipótesis para dar cuenta de hechos que nos sorprenden y que no tienen una explicación a partir de reglas generales. La lógica de la abducción incluye así a la creatividad y a la sorpresa (Pulice, Zelis y Manson, 2007).

Michel Fariña (2015) propone esta innovación metodológica en la articulación entre cine y psicología considerando que el análisis debe estar circunscrito a los personajes y al relato del film, y resaltando el valor del detalle leído como una singularidad en situación, y la posibilidad de establecer una conjetura o hipótesis clínica al respecto (Michel Fariña y Gutiérrez, 1999; Michel Fariña y Solbakk, 2012; Michel Fariña, 2015; Cambra Badii, 2016; Michel Fariña y Tomas Maier, 2016).

Asimismo, nuestra propuesta radica en dar un paso más sobre este desarrollo, y tomar en cuenta no sólo la narrativa del film, sino también los recursos técnico-estilísticos. Esta construcción del espectador, definitivamente singular y novedosa, se basa en los datos experimentales del film (la obra existe, en efecto) pero incluye elementos ligados a las intuiciones, a la espontaneidad, y a la lectura singular misma. Esta operación conceptual, producida a partir de la experiencia propia como espectador, pero también 
en conexión con los saberes previos e intuiciones sobre el tema, es de vital importancia y requiere ser revalorizada en el estudio del cine y las ciencias sociales, y a psicología en particular. Implica, asimismo, la interrogación acerca de qué nos enseña, a los psicólogos, la experiencia del cine (Michel Fariña, 2012).

Esta pregunta, de vital importancia, implica invertir el estudio de la obra cinematográfica en los términos planteados por Aumont y Marie (2006), tan difundidos hasta nuestros días. Un ejemplo paradigmático de este modo de lectura en el ámbito psi es la del filósofo esloveno Slavoj Zizek (1994a, 1994b, 2000), cuyo talento se despliega en innumerables escritos y aportes de articulación entre cine y psicoanálisis, que aplican los conceptos del psicoanálisis lacaniano a distintas obras de la cinematografía moderna.

Desde nuestro punto de vista metodológico, se trata de hace justamente del movimiento contrario: el desafío está en poder introducir la cuestión de poder pensar conceptualmente a partir de lo que el cine trae a la disciplina psicológica como forma de interrogarla y de crearla, y no al revés, interpretando todos los contenidos como si fueran conceptos acabados.

El cine no solamente actúa como ejemplificaciones o ilustraciones de contenidos ya existentes, sino que muchas veces permiten estructurar nuevos modelos metodológicos de comprensión o incluso de creación de problemas complejos, en un equilibrio que incluye tanto a la deliberación sobre los conceptos como la experiencia estética y artística de la narrativa audiovisual.

En las investigaciones anteriores (UBACyT 2011-2014 y 2014-2017) nos hemos preguntado si a través de un recorte o fragmento cinematográfico puede ampliarse el conocimiento sobre una situación determinada, estudiada previamente desde el conocimiento disponible en el estado del arte. Hemos planteado la posibilidad de que las emociones provocadas por las imágenes y la experiencia misma del cine, a través de conocer las relaciones interpersonales entre los personajes implicados, luego de observar sus reacciones e involucrarse con ellos, al producirse en el espectador nuevos pensamientos y sentimientos suscitados por la situación, producen un singular acercamiento a los conceptos, e incluso la posibilidad de pensar conceptos nuevos a partir de la experiencia cinematográfica.

Teniendo en cuenta los antecedentes estudiados en relación con la Psicología, podemos señalar que así como la narrativa cinematográfica nos permite indagar vías de acceso a la clínica con los pacientes (por ejemplo a través de la cineterapia analítica, Cambra Badii et al, 2017), se convierte también en una vía privilegiada para estudiar los dilemas de nuestra práctica cotidiana como psicólogos, ya que al mostrar nuevos problemas o presentarlos en una complejidad insospechada despierta distintos afectos, que después pueden ponerse en palabras.

Por otra parte, considerando que el formato audiovisual no sólo permite acercarse a situaciones novedosas, problemas y dilemas de nuestro campo profesional, sino que también permiten elaborar conceptos nuevos en relación a ellos (Cabrera, 1999), podemos preguntarnos: ¿de qué manera el cine modela el pensamiento psicológico? ¿Cómo surgen conceptos nuevos a partir de la narrativa cinematográfica? ¿Cómo pueden integrarse en una matriz metodológica (Samaja, 2004) que nos permita pensar en el cine como registro del mundo contemporáneo, pero también como creador de sus representaciones?

Los modelos metodológicos que buscaremos sistematizar representan una nueva forma de trabajar con las narrativas audiovisuales, constituyéndolas científicamente en esquemas reconocibles y replicables en distintas áreas y disciplinas científicas. Evidentemente, la cuestión social de producción del conocimiento a través del cine permite repensar en distintos escenarios y modelos para las ciencias sociales y humanas.

Para poder pensar los modelos metodológicos, nos basamos en la conceptualización de los modelos mentales, es decir, representaciones internas de los objetos o fenómenos, que poseen características internas comunes, a la manera de analogías funcionales (Johnson-Laird, 1983). Estas analogías funcionales tienen un carácter más abstracto que la información del objeto o fenómeno, pero son 
presentadas como “análogas estructurales del mundo” (Moreira, 1998, p. 5). Desde nuestra concepción, en estos modelos metodológicos encontramos un paso más, una co-construcción, que podríamos ubicar entre la narrativa audiovisual y el acto del espectador, que modifica el film de acuerdo con un acto de lectura. Es decir, no es una fotocopia o una analogía estructural del film, sino que en el acto de lectura del film hay un aspecto subjetivo del espectador.

Estos modelos metodológicos trascienden entonces el modelo didáctico de las herramientas de aplicación e interrogación, para interesarse por las formas de construcción activas de los espectadores. Para ello, es necesario tomar en cuenta la dimensión singular del formato audiovisual. Esta es una de las dos manifestaciones de lo audiovisual, que se incluye en un doble movimiento: por un lado, lo particular (lo común a un determinado momento socio-histórico, las normativas, los códigos grupales compartidos), y por otro, lo universal-singular, la singularidad en situación, es decir, aquellas coordenadas precisas que tiene una situación que la diferencian de las demás y que, en algunos casos, amplían el universo conocido previamente (Michel Fariña, 2001; Michel Fariña y Solbakk, 2012). Consideramos que es a través de esta singularidad que el espectador puede empatizar con el contenido de la narrativa, ya que visualiza elementos de la dimensión subjetiva -detalles de la vida de los personajes y de la trama, que permiten hacer puentes con elementos comunes con su vida profesional y cotidiana, y a su vez identificarse con estados de ánimo, actitudes o acciones llevadas a cabo por los personajes.

El abordaje de las singularidades situacionales que mencionamos es, a su vez, un sistema epistemológico diferente a la intención generalizante que suele utilizarse en algunos contextos científicos. Cada una de las analogías cinematográficas analizadas, puede pensarse a la manera de un paradigma de la singularidad. Tal como señala Giorgio Agamben, cuando se configura un paradigma, esto:

\footnotetext{
implica el abandono sin reservas del particular-general como modelo de la inferencia lógica. La regla (si aún puede hablarse aquí de regla) no es una generalidad que preexiste a los casos singulares y se aplica a ellos, ni algo que resulta de la enumeración exhaustiva de los casos particulares. Más bien es la mera exhibición del caso paradigmático la que constituye una regla, que, como tal, no puede ser ni aplicada ni enunciada (Agamben, 2010, p. 10).
}

Esta posibilidad de pensar al cine en relación con la construcción de una singularidad en situación permite desplegar, a partir de recortes de pocos minutos de duración, una verdadera ocasión de pensamiento donde se despliega la subjetividad de los personajes y del propio espectador, atravesado por la escena.

\section{Conclusiones: líneas de investigación actuales y futuras}

\section{Las ideas ya no se escriben en papel. Se escriben en pantallas. (Ray, en Gimeno, 2010)}

Habiendo establecido una sistematización del estado del arte respecto del estudio sobre cine para su articulación con la Psicología, hemos propuesto pensar en la posibilidad de crear modelos metodológicos para su estudio, que contribuya a la comprensión de problemas complejos de la Psicología y que tengan en cuenta los efectos que se generan en el espectador, los fenómenos de comprensión del contenido y los conceptos que se representan en el interior de la narrativa cinematográfica, así como también la dimensión subjetiva del discurso cinematográfico.

Esto implica jerarquizar el valor singular de la propia lectura del espectador en relación con su experiencia cinematográfica, dejándose transformar por lo que allí acontece, y poniendo en tensión aspectos conceptuales que no son universos cerrados.

Para el futuro de la investigación, conjuntamente con la delimitación de estos modelos metodológicos, consideramos necesario volver a preguntarnos por las distintas modalidades del formato de la narrativa audiovisual, ya que en la actualidad consideramos sumamente interesante el estudio del cine y de las series. 
Desde hace dos décadas, las series se constituyen como formatos narrativos audiovisuales privilegiados: diariamente, millones de personas siguen distintos géneros y formatos (desde la tradicional sitcom hasta miniseries de escasos episodios y un formato similar al cinematográfico) desde la pantalla de su celular, tablet o notebook. El espectador se independiza de la sala de cine y de las fechas de estreno de las películas, sumergiéndose de lleno en el ritmo de las series, que atrapan con sus lanzamientos por temporadas completas mediante un simple click en plataformas como Netflix o Amazon. Por la potencia de su difusión, las series se han constituido como un relevo del cine para el público masivo. Esto no se debe únicamente a las múltiples posibilidades y dispositivos que las nuevas tecnologías brindan, sino que, en una sociedad permanentemente instalada en la hiperactividad y esclava de la falta de tiempo, la vida actual exige entretenimientos cortos y accesibles (Bort Gual, 2010).

Entendemos, junto con Gèrard Wajcman, que la serie americana funda una gramática nueva y singular que rompe con las formas del relato propias del cine, la novela o la pintura, e instituye un "relato del mundo" que da cuenta de la época. Nuestro mundo, entonces, estaría estructurado como una serie americana (Wajcman, 2010).

Las series constituyen plataformas narrativas que nos permiten acceder a las representaciones actuales como indicadores privilegiados de una determinada cultura de época, con ritmos distintos a los de las producciones cinematográficas. Entenderlas no sólo como fenómeno de consumo sino más bien en su dimensión semiótica (Lotman, 2000) posibilita utilizarlas como fuente de información en un análisis cualitativo de su contenido, que nos permite emplazar, una vez más, la pregunta metodológica: ¿qué nos enseña, a los psicólogos, la experiencia de la narrativa cinematográfica? (Michel Fariña, 2012).

Tal como señala Carrión (2014) las series vienen a reemplazar al cine, así como el cine ha reemplazado a la literatura de los siglos XIX y XX como forma de relato predominante en términos de consumo, “amplificando la percepción o el sentido de las otras modalidades discursivas” (Carrión, 2014, pp. 49$50)$.

Asimismo, resulta interesante adentrarnos en los estudios que combinan la semiótica y el análisis de consumos culturales, ya que se entiende a las series no sólo en su dimensión narrativa, sino que incorpora el análisis de los espectadores, denominados usuarios. Henry Jenkins (2003) y Carlos Scolari (2013) proponen el estudio de las narrativas transmedia haciendo énfasis en la colaboración de los usuarios en la expansión del relato literario en su traspolación al cine y a las series, y la transformación a través de distintas plataformas virtuales tales como blogs, Twitter, entre otras.

El cine trasciende sus fronteras originales y se incorporan nuevos aspectos y conceptos a través de las series y de conceptualizaciones nuevas, que requieren ser reelaborados, repensados, resignificados, en nuevos avances científicos sobre esta disciplina en conexión con la psicología y otras ciencias sociales.

\section{Agradecimientos}

Este trabajo fue realizado en el marco de la Práctica Profesional y de Investigación 823 de la Facultad de Psicología, Universidad de Buenos Aires (Prof. Titular Juan Jorge Michel Fariña) y el proyecto de la Secretaría de Ciencia y Técnica de la Universidad de Buenos Aires (UBACyT) 20020170200229BA "Pensar el cine. La narrativa de películas y series como matriz metodológica para el tratamiento de problemas complejos”.

\section{Referencias}

Agamben, G. (2010). Signatura rerum. Sobre el método. Buenos Aires: Adriana Hidalgo.

Andreas-Salomé, L. ([1913] 1977). Aprendiendo con Freud. Barcelona: Laertes. 
Aumont, J., Bergala, A., Marie, M., y Vernet, M. (2011). Estética del cine. Espacio fílmico, montaje, narración, lenguaje. Buenos Aires: Paidós.

Aumont, J., y Marie, M. (2006). Diccionario teórico y crítico del cine. Buenos Aires: La Marca Editores.

Badiou, A. (2004). El cine como experimentación filosófica. En Yoel, Gerardo, Pensar el cine 1: imagen, ética y filosofía (pp.23-35). Buenos Aires: Manantial.

Badiou, A. (2011). Imágenes y palabras. Escritos sobre cine y teatro. Buenos Aires: Manantial

Bajtin, M. (1982). El problema de los géneros discursivos. En Estética de la creación verbal. México: Siglo XXI

Barthes, R. (1970). El efecto de realidad. En Lo verosímil (95-101). Buenos Aires: Tiempo Contemporáneo

Benasayag, A. (2017) La hipótesis de la cinefilia docente. El cine de ficción en la escuela media argentina. Revista Digital do LAV, 10(2), pp. 56-78

Bergala, A. (2007). La hipótesis del cine. Pequeño tratado sobre la transmisión del cine en la escuela y fuera de ella. Barcelona: Laertes.

Bergson, H. (2006) Materia y memoria. Ensayo sobre la relación del cuerpo con el espíritu. Buenos Aires: Cactus.

Bergson, H. (2016). Memoria y vida. Madrid: Alianza

Bettetini, G. (1984). Tiempo de la expresión cinematográfica: la lógica temporal de los test audiovisuales. México: Fondo de Cultura Económica.

Bort Gual, I. (2010) Nuevos paradigmas teóricos en las partículas narrativas de apertura y cierre de las series de televisión dramáticas norteamericanas contemporáneas. En Memorias II Congreso Internacional Latina de Comunicación Social. Universidad de la Laguna.

Cabrera, J. (1999): Cine: 100 años de filosofía. Una introducción a la filosofía a través del análisis de películas. Barcelona: Gedisa.

Calvert, B., Casey, N., Casey, B., French, L., y Lewis, J. (2007). Television studies: The key concepts. London: Routledge.

Cambra Badii, I. (2014) La narrativa cinematográfica como Vía de Acceso a la Complejidad en Bioética. Tesis de Doctorado en Psicología, Universidad del Salvador, Buenos Aires, Argentina, Inédita.

Cambra Badii, I. (2016). Psicología, Bioética y Narrativa cinematográfica: un análisis cualitativo de producciones de estudiantes sobre conflictos bioéticos relacionados con la identidad. Revista Latinoamericana de Bioética, 16, 31-2, pp. 16-39.

Cambra Badii, I., Mastandrea, P., Paragis, P., Tomas Maier, A., González Pla, F., Michel Fariña, J. J. (2017). Cine aplicado a la Psicología: el abordaje ético-clínico de las Tecnologías de Reproducción Humana Asistida. En Premio Facultad de Psicología (pp. 11-39), Buenos Aires: Universidad de Buenos Aires.

Canudo, R. (1914). Manifiesto de las siete artes. En: Textos y Manifiestos del Cine. Estética. Escuelas. Movimientos. Disciplinas. Innovaciones.

Carrión, J. (2014). Teleshakespeare. Las series en serio. Buenos Aires: Interzona 
Casetti, F., y Di Chio, F. (1994) Cómo analizar un film. Madrid: Cátedra

Casetti, F., y Gromegna, A. G. (1989). El film y su espectador. Madrid: Cátedra.

Chion, M. (1993). La audiovisión. Introducción a un análisis de la imagen y el sonido. Barcelona: Paidós.

Dalmasso, M.T. (2005) Reflexiones semióticas. Estudios, 17, 11-20.

Dark, M. L. (2005). Using science fiction movies in introductory Physics. The Teacher Physics, 43, 463465.

Deleuze, G. (1984) Estudios sobre cine 1. La imagen - movimiento. Barcelona: Paidós.

Deleuze, G. (1987) Estudios sobre cine 2. La imagen - tiempo. Barcelona: Paidós.

Ferres, J. (2014). Las pantallas y el cerebro emocional. Barcelona: Gedisa.

García Borrás, F. J. (2008), Bienvenido Mister cine a la enseñanza de las ciencias. Revista Eureka sobre Enseñanza y Divulgación de las Ciencias, 6(1), 79-91.

Gaudreault, A., Jost, F., y Pujol, N. (1995). El relato cinematográfico: cine y narratología. Barcelona: Paidós.

Genette, G. (1989). Figuras III. Barcelona: Lumen

Gimeno, S. (2010). Series cum laude. Madrid: El País del 10 de abril de 2010.

Ginzburg, C. (2008). Indicios. Raíces de un paradigma de inferencias indiciales. En Mitos, problemas, indicios. Morfología e historia. Barcelona: Gedisa.

Hernández Figaredo, P., Peña García, F. (2013). El cine como herramienta en la docencia de Psiquiatría. Revista Humanidades Médicas, 13, (1), 244-265.

Jenkins, H. (2003): “Transmedia storytelling: Moving characters from books to films to videogames can make them stronger and more compelling”. Technology Review. Disponible en: $<$ http://www.technologyreview.com/biotech/13052>

Johnson- Laird, P. (1983). Mental Models. Towards a Cognitive Science of Language, Inference, and Consciousness. Cambridge: Harvard University Press.

Jost, F. (2002). El ojo cámara: entre el film y la novela. Buenos Aires: Catálogos.

Laso, E. (2018). El ojo maravilloso. Buenos Aires: Rojo

Lewkowicz, Ignacio (2002). Particular, Universal, Singular. En Michel Fariña, J. J. Ética: un horizonte en quiebra (pp. 57-63). Buenos Aires: Eudeba.

Lotman, Y. (2000). El lugar del arte cinematográfico en el mecanismo de la cultura. En La Semiosfera III (pp.123-137), Madrid: Frónesis Cátedra.

Mason, J. (1996). Qualitative Researching. Londres: Sage.

Mateus, J.C. (2017) Las teleseries también educan. Una defensa de las ficciones televisivas como dispositivos de aprendizaje. En: Cappello, G. (ed.) Ficciones cercanas. Televisión, narración y espíritu de los tiempos. (pp. 179-195) Lima: Universidad de Lima. Fondo Editorial. 
Metz, C. ([1972]2000). Ensayos sobre la significación en el cine. Buenos Aires: Paidós

Michel Fariña, J.J. (2001). La ética en movimiento. Fundamentos en Humanidades. Facultad de Ciencias Humanas de San Luis, 1(2), 13-20.

Michel Fariña, J.J. (2006). El doble movimiento de la ética contemporánea: una ilustración cinematográfica. En Salomone, G. Z. y Domínguez, M. E., La transmisión de la ética. Clínica y deontología. Vol. I: Fundamentos (pp. 19-26). Buenos Aires: Letra Viva.

Michel Fariña, J. J. (2012) Un abordaje (bio) ético: lo que el cine nos enseña sobre la tartamudez. En Michel Fariña, J. J. y Solbakk, J. H. (2012): (Bio)ética y Cine. Tragedia griega y acontecimiento del cuerpo (pp.151-159). Buenos Aires: Letra Viva.

Michel Fariña, J. J. (2015). Ética y cine: el método clínico-analítico de lectura de películas y sus aportes a la psicología. Tesis de Doctorado en Psicología, Universidad de Buenos Aires, Buenos Aires, Argentina, Inédita.

Michel Fariña, J.J, y Gutiérrez, C. (1999). Ética y Cine. Buenos Aires: JVE Ediciones / Eudeba.

Michel Fariña, J. J., y Solbakk, J. H. (Comps.) (Bio)ética y cine. Tragedia griega y acontecimiento del cuerpo. Buenos Aires: Letra Viva.

Michel Fariña, J.J, y Tomas Maier, A. (2016). ¿Cómo leer un film? La formación ética a través del cine y la virtualidade. Informática na Educação: teoria e prática, 19 (1), pp. 69-83.

Moreira, M. A. (1998). Mental models. Investigações em Ensino de Ciências, 1 (3), p. 193-232.

Morin, E. (2001). El cine o el hombre imaginario. Barcelona: Paidós

Perales Palacios, F.J. (2006), Uso (y abuso) de la imagen en la enseñanza de las ciencias. Enseñanza de las ciencias, 24(1), 13-30

Piscitelli, A. (2012). Video TV, ergo sum. Cuando la cultura audiovisual también sirve para pensar(se) y hacer pensar. En G. Orozco (coord.), TVMorfosis: la televisión abierta hacia una sociedad de redes (pp. 98-107). México: Universidad de Guadalajara / Tintable.

Pulice, G., Zelis, O., y Manson, F. (2007). Investigar la subjetividad. Buenos Aires: Letra Viva.

Ricoeur, P. (2006). La vida: un relato en busca de narrador. Ágora, 25 (2), 9-22

Salomone, G. Z. (2013). Responsabilidad profesional: Las perspectivas deontológica, jurídica y clínica. En Discursos institucionales, lecturas clínicas. Dilemas éticos de la psicología en el ámbito jurídico y otros contextos institucionales (pp. 94-107), Buenos Aires: Dynamo.

Samaja, J. (2004). Proceso, diseño y proyecto en investigación científica. Buenos Aires: JVE Editores.

Sartori, G. (1998). Homo videns. La sociedad teledirigida. Madrid: Taurus.

Scolari, C. (2013). Narrativas transmedia. Cuando todos los medios cuentan. Barcelona: Deusto

Sel, S., y Gagioli, L. (2002). A propósito de ‘Reflexiones sobre una estética del cine’ (1913), Coloquio Georgy Lukács, UBA, Cedinci.

Taylor, S.J. y Bogdan, R (2013). Introducción a los métodos cualitativos de investigación. Barcelona: Paidós. 
Triquell, X. (2012). Contar con imágenes: Una introducción a la narrativa audiovisual. Córdoba: Brujas

Vollet, M. (2006). Imágenes, percepción y cine en Bergson y Deleuze. Eidos: Revista de Filosofía de la Universidad del Norte, 5, pp. 70-93

Wajcman, G. (2010). Tres notas para introducir la forma 'serie'. Revista del Departamento de Estudios Psicoanalíticos sobre la Familia - Enlaces, 12, 15. Buenos Aires: Grama Ediciones

Zimmerman, D. (2000). Contornos de lo Real. La verdad como estructura de ficción. Buenos Aires: Letra Viva.

Zizek, S. (1994a). ¡Goza tu síntoma! Jacques Lacan dentro y fuera de Hollywood. Buenos Aires: Nueva Vision.

Zizek, S. (1994b). Todo lo que usted siempre quiso saber sobre Lacan y nunca se atrevió a preguntarle a Hitchcock. Buenos Aires: Manantial

Zizek, S. (2000). Mirando al sesgo: una introducción a Jacques Lacan a través de la cultura popular. Barcelona: Paidós. 